\title{
Article \\ What Can L2ers Tell Us about Codeswitching? Mood Selection in Spanish
}

\author{
Nick Feroce ${ }^{1,2}$, Ana de Prada Pérez ${ }^{3, *(\mathbb{D})}$ and Lillian Kennedy ${ }^{4}$ \\ 1 Department of Linguistics, University of Kansas, Lawrence, KS 66045, USA; \\ nferoce1@gmail.com or nick.feroce@lexialearning.com \\ 2 Impact and Efficacy Research, Lexia Learning, Concord, MA 01742, USA \\ 3 Department of Spanish and Latin American Studies, School of Modern Languages, Literatures, and Cultures, \\ Maynooth University, Maynooth, Co. Kildare, Ireland \\ 4 Independent Researcher, Orlando, FL 32837, USA; lillyek91@gmail.com \\ * Correspondence: ana.depradaperez@mu.ie
}

Citation: Feroce, Nick, Ana de Prada Pérez, and Lillian Kennedy. 2021. What Can L2ers Tell Us about Codeswitching? Mood Selection in Spanish. Languages 6: 200. https:// doi.org/10.3390/languages6040200

Academic Editor:

Bryan Koronkiewicz

Received: 29 July 2021

Accepted: 23 November 2021

Published: 3 December 2021

Publisher's Note: MDPI stays neutral with regard to jurisdictional claims in published maps and institutional affiliations.

Copyright: () 2021 by the authors. Licensee MDPI, Basel, Switzerland. This article is an open access article distributed under the terms and conditions of the Creative Commons Attribution (CC BY) license (https:// creativecommons.org/licenses/by/ $4.0 /)$.

\begin{abstract}
An increasing amount of research shows that bilinguals that engage in codeswitching (CS) may show different patterns of usage and sensitivity to particular linguistic structures depending on community norms. Additionally, proficiency may play a different role in sensitivity to codeswitched utterances depending on speaker background, as well as the structure investigated. In this study, we aim to examine how bilinguals not exposed to CS in the community rate CS vs. unilingual sentences involving mood selection in Spanish. In an online acceptability judgment task (AJT), 20 Spanish L2ers rated sentences containing verbs in the indicative and subjunctive mood in restrictive relative clauses manipulated for the specificity of the antecedent in two separate sessions: a Spanish monolingual mode and a CS session. The L2ers did not show evidence of a CS effect and maintained a mood distinction according to the specificity of the antecedent both in unilingual and codeswitched sentences. These results are in contrast with the results previously reported for Spanish heritage speakers (HSs), where a CS effect is attested in the loss of preference for the subjunctive in nonspecific relative clauses in the CS vs. the monolingual Spanish condition. Additionally, this distinction is found at both lower and higher proficiency levels. The differences between these speakers and HSs are consistent with data from previous research on CS effects on phonology and Det-N switches. We argue that exposure to community norms is necessary for the acquisition of patterns not related exclusively to the grammaticality of switch junctures (I-language).
\end{abstract}

Keywords: codeswitching; subjunctive; Spanish-English bilingualism; L2ers; relative clauses; mood selection

\section{Introduction}

Multilinguals' languages are activated to different degrees depending on their communicative context. Grosjean (2001) coined the term language mode to refer to a continuum of language activation bilinguals may find themselves in: from contexts with interlocutors that only speak language $A$, where language $A$ is maximally activated in the bilingual and $B$ as inhibited as it can be, to the opposite context, where language B is maximally activated. Crucially, code-switching (CS), or the alternation of languages within a single speech act, is envisioned to fall in the middle of this continuum.

CS has received extant attention from sociolinguists interested in bilingual communities, as it offers a window into community practices (e.g., Torres Cacoullos and Travis 2018); psycholinguists, as it informs our understanding of bilingual processing (e.g., Moreno et al. 2002); and formal linguistics (e.g., MacSwan 2013), as it can offer valuable information about the structure of languages (López 2020). Formal perspectives have focused on restrictions specific to CS, such as structural constraints and switch points (e.g., the Functional Head Constraint by Belazi et al. 1994; or the Matrix Language Frame by Myers-Scotton 
and Jake 2009) in contrast with approaches that do not assume CS-specific constraints (MacSwan 2013, among others), as well as directionality of switching (Suurmeijer et al. 2020), and the use of default options, as in the use of the masculine default (e.g., Balam 2016; Valdés Kroff 2016) or bilingual verb compounds in CS (e.g., Balam et al. 2014) (cf. Deuchar 2020, for a recent review).

There is consensus in the literature that speakers are sensitive to the grammaticality of switches. To the best of our knowledge, previous literature on L2 CS has exclusively focused on the grammaticality of CS switch points (I-language-focused CS research, Toribio 2017). Beyond L2 learners, CS research with different types of bilinguals, such as heritage speakers (HSs), have also revealed interesting patterns (e.g., the contrast in structures used or rated by bilinguals when they were in two different sessions or blockings: a Spanish-only session and a CS session). In that case, studies examined the effect of CS on specific linguistic properties, where comparison between monolingual Spanish and CS sessions were drawn in the examination of a specific linguistic feature (e.g., Torres Cacoullos and Travis 2018). This CS research, thus, takes a variationist approach, focusing on the effects of usage and, thus, switches the focus from the I-language to the E-language (Toribio 2017). For instance, the same participants used the feminine determiner differently in Spanish monolingual vs. Spanish-English CS sessions in Denbaum and Prada Pérez (2020). Other linguistic properties that have been examined comparing monolingual vs. CS sentences include subject pronoun expression (Prada Pérez 2018; Toribio 2004; Torres Cacoullos and Travis 2011, 2016, 2018), copula choice (Prada Pérez and Hernández 2017), gender assignment and agreement (Denbaum and Prada Pérez 2020), and mood selection (Prada Pérez et al. 2021; Raymond 2012). These studies report differences in pronunciation, production, or rating of certain forms when they are in bilingual mode (CS) vs. in monolingual mode. Of particular interest is the fact that the Spanish heritage speakers in Prada Pérez et al. (2021) and Raymond (2012) reported a CS effect that consisted of a decrease in association of the Spanish subjunctive with the semantic aspects that it is usually associated with (i.e., nonspecificity in relative clauses).

Crucially, little is known about CS in L2ers, although there is much to be gained from understanding their CS preferences (Koronkiewicz 2018; Potowski 2009). There have been proposals that indicate that CS ability is derived from proficiency in each of the languages (Giancaspro 2013, 2015; Guzzardo Tamargo and Dussias 2013; Lipski 2014, 2016; Montoya 2020; Potowski and Bolyanatz 2012; Toribio 2001). In contrast, Torres Cacoullos and Travis (2018) defend that CS is acquired through exposure to the community. Further evidence for this comes from recent research that has reported differences across various bilingual communities for determiner-noun switches (Blokzijl et al. 2017; Królikowska et al. 2019 as reported in Beatty-Martínez and Dussias 2019), as well as compound verbs (Balam et al. 2020). Koronkiewicz (2018) reveals that a combination of both proficiency and exposure to CS are predictors in convergence with CS patterns of simultaneous bilinguals.

On the one hand, previous literature indicates L2ers acquire the ability to distinguish grammatical from ungrammatical CS sentences (I-language), while, on the other, there is more to CS than switch junctures (E-language). There are certain patterns in CS, such as the effects of CS on variable forms (e.g., subject pronoun expression or mood selection in relative clauses when speakers are CS vs. when they are using only one of their languages), that have, to the best of our knowledge, never been explored in L2ers. It is possible that the examination of CS effects on variable forms may reveal where exposure to community norms is relevant to CS. Beatty-Martínez and Dussias (2017) point out that there may be different predictions in CS depending on community exposure and proficiency. In our case, proficiency in Spanish would correlate with a monolingual Spanish mood selection in relative clauses, i.e., indicative in specific and subjunctive in nonspecific relative clauses. Since HSs do not associate the subjunctive with nonspecificity in relative clauses in CS, while they do in monolingual Spanish sentences, this knowledge cannot be derived from Spanish grammar and, thus, not from proficiency in Spanish, but from community norms, i.e., exposure to Spanish-English CS. Similarly, the use of bilingual compound verbs 
(Balam et al. 2014; González-Vilbazo and López 2011), i.e., the use of auxiliary verbs as light verbs in CS, a strategy that may be unique to CS, cannot be derived from knowledge of the two grammars involved. In this research, the focus is on the use in CS and, thus, the E-language. In fact, Balam et al. (2020) find differences in the bilingual compound verbs across Spanish-English (Creole) communities. We argue here similarly that L2ers not exposed to the indicative default attested in CS in Spanish-English HSs can further exemplify the role of exposure to community norms in CS acquisition because the use of mood choice is different in CS than in monolingual Spanish. With this idea in mind, in this paper, we examine the effect that bilingual mode (Grosjean 2001), CS, in particular, has on the ratings of the indicative and the subjunctive verbal forms in relative clauses in Spanish by L2ers. This paper can inform our understanding of the role of exposure to community CS norms in the presence of CS effects by examining the effect that CS has (or not) on mood selection in Spanish L2ers' ratings of monolingual and CS sentences.

\section{Previous Research}

\subsection{Mood Selection in Spanish Relative Clauses}

Mood choice in relative clauses in Spanish carries meaning as it constitutes a polarity use of the subjunctive (Giancaspro 2017, and references therein). In (1), mood is contextually selected and contributes to meaning.

(1) $\mathrm{Kim}_{i}$ busca

Kim look for [3SG] a racquet

$s u_{i}$ saque.

her serve.

'Kim is looking for a tennis racquet that improves her serve.' Giancaspro (2017, p. 58) una raqueta de tenis que mejore/mejora

of tennis

that improve-3SG-SUBJ/INDIC

In (1), both the indicative and the subjunctive are grammatical. When the indicative is used, though, the antecedent is interpreted as specific or referential, whereas when the subjunctive is used, the antecedent is interpreted as nonreferential or attributive (Borgonovo et al. 2015). Since both moods are possible, relative clauses constitute a variable context of use of the subjunctive. In these variable uses of the subjunctive, contextual information determines which mood is grammatical, but the distribution is not as categorical as in obligatory uses of the subjunctive. For example, in obligatory contexts, Spanish-dominant speakers in New York City (NYC) used the subjunctive more than $90 \%$ of the time, while in variable uses, specifically with adjectival clauses of nonexistent or indefinite antecedents, they used it only $84 \%$ of time (Viner 2016). This result has also been replicated numerically in more experimental tasks. van Osch and Sleeman (2018) reported that monolingual Spanish speakers used the subjunctive almost $100 \%$ of the time in obligatory contexts and $90 \%$ of the time with variable uses, i.e., with nonspecific relative clauses.

The specificity of the antecedent may be derived from a variety of markers in Spanish: the lexical semantics and grammatical aspect of the matrix verb, as well as contextual factors. Intensional predicates, such as buscar 'to look for', in the matrix clause do not presuppose the existence of the direct object, in contrast with nonintensional predicates, such as encontrar 'to find', which presuppose their existence. Consequently, if the direct object of an intensional predicate is the antecedent of a relative pronoun, the relative clause will be in the subjunctive. Similarly, the use of perfective forms in the matrix verb implies a specific interpretation (Giancaspro 2017). The sentences in the present study used identifiable referents in the specific antecedent condition and negated main clauses, which are necessarily nonspecific, to force a nonspecific interpretation of the antecedent in the nonspecific antecedent condition. In particular, we negated a main clause antecedent with either sentential negation or a negative pronoun or determiner, such as nada ('nothing'), nadie ('nobody'), or ningún, o/a ('none').

The complexity of mood selection in relative clauses has attracted the attention of researchers interested in the acquisition of Spanish by L2 speakers (Collentine 2010). Variationist studies have primarily examined the development of the subjunctive across different semantic categories (e.g., volition, comment, uncertainty). Collentine (1995), for instance, 
reports on the use of the subjunctive in relative clauses as being difficult for intermediate learners. Additionally, most of these studies focus on the subjunctive in nominal and adverbial clauses (Collentine 1995; Geeslin and Gudmestad 2008, 2010; Gudmestad 2006, 2012; Quesada 1996, 1998) and generally observe native-like use of the subjunctive at higher levels of L2 proficiency. Under a generative approach, Borgonovo and colleagues have undertaken several studies investigating L2 acquisition of the Spanish subjunctive (Borgonovo et al. 2006, 2008, 2015). While Borgonovo and Prévost (2003) found that advanced learners were sensitive to mood distinctions in verbal complements, Borgonovo et al. (2015) note that relative clauses pose difficulties for learners. Overall, learners generally accepted the subjunctive with nonspecific determiner phrases (DPs) and the indicative with specific DPs. With nonspecific DPs, however, the subjunctive was accepted, while the indicative was not consistently rejected, in line with Leonetti Jungl's (1999) claim that the subjunctive is linked to nonspecificity, but the indicative is not necessarily linked to specificity. Similarly, Montrul (2011) and Montrul and Perpiñán (2011) showed that L2ers exhibit difficulty with mood selection at lower and intermediate levels of proficiency.

\subsection{CS Effects on Mood Selection in Spanish}

There have been several studies contrasting bilingual speaker speech when they are codeswitching vs. when they are speaking in just one of their languages. Some of these studies in the area of morphosyntax have examined subject expression in Spanish, reporting higher use of overt pronominal subjects in Spanish when Spanish-English bilinguals are codeswitching than when they are in monolingual Spanish mode (Prada Pérez 2018; Toribio 2004; Torres Cacoullos and Travis 2011, 2016). Toribio (2004), for instance, analyzed the production of fairytales in Spanish-only and Spanish-English CS by two Mexican-American bilinguals. She reported that in the CS narratives there was a higher number of pragmatically infelicitous overt pronominal subjects than in the Spanish-only narratives. The trend to use more overt pronominal subjects in Spanish when participants are codeswitching was also attested in other types of data, such as corpus data in Torres Cacoullos and Travis (2011, 2016) and elicited production in Prada Pérez (2018). CS effects have also been explored with copulative verbs in Spanish. Prada Pérez and Hernández (2017) examined copula choice in a contextualized Acceptability Judgement Task (AJT) by Caribbean Spanish HSs living in Florida and found that participants overused the default copula ser, 'to be', in the CS session more than in the Spanish-only session. Crucial to our paper is the CS effects attested in mood choice in Spanish. Raymond (2012) examined mood choice in intensional and obligatory contexts through a three-point scalar grammaticality judgment task (GJT) in a group of 30 second-generation HSs from South California. Participants rated 44 sentences that consisted of four variations of 11 sentences, as in (2):

(2) Example of sentence variations in Raymond (2012, p. 222)
a. Es muy importante [que vengas con nosotros].
(monolingual, subj.)
b. Es muy importante [que vienes con nosotros].
(monolingual, indic.)
c. It's really important [que vengas con nosotros].
d. It's really important [que vienes con nosotros].
'It is really important that you come with us'.
(bilingual, subj.)
(bilingual, indic.)

The four variations of each of the 11 sentences resulted from the manipulation of language mode (bilingual vs. monolingual) and mood (indicative vs. subjunctive). He showed that, in monolingual Spanish sentences, the indicative, as in (2b), was almost categorically rejected (Mean rating: $0.3 / 3$ ), while, in CS sentences, it (2d) was accepted at a higher rate (Mean rating: 1.6/3). Lastly, in Prada Pérez et al. (2021), which involved the exact same design and materials as the current study, 24 Spanish HSs rated sentences with relative clauses manipulated for specificity of the antecedent and mood in two sessions: a Spanish monolingual and a CS session. Participants exhibited a CS effect, whereby the preference for the subjunctive with nonspecific antecedents was not significant in the CS session, while it was in the Spanish monolingual session. These results are relevant to the current study, since they indicate that there is a CS effect on mood selection in HSs. 
Specifically, it shows that the association of the subjunctive with nonspecificity is present in monolingual mode but not in bilingual mode. It resembles the masculine default effect in Spanish-English CS in some communities in the U.S. in that, in CS, the grammar of the Spanish segment does not follow monolingual Spanish tendencies, and a default form is used instead. For L2 learners, this knowledge cannot be derived from proficiency in Spanish, as it is an aspect of CS not related to the I-language.

These studies all have in common the inclusion of early bilinguals, either secondor third-generation HSs or speakers from rural communities where Spanish has been spoken beyond the third generation. These CS patterns may be argued to not be derived from the general linguistic properties of Spanish and, thus, may be acquired from the community. Acquiring the mood alternation in relative clauses or gender agreement in Spanish would not lead speakers not exposed to CS in the community to use the masculine or the indicative default in CS. In the review in Parafita Couto et al. (2021) an emphasis is placed on further examining the role that external factors, such as community norms, play in the asymmetries reported in previous CS literature. This paper examines a different structure, mood selection in relative clauses, as Raymond (2012) and Prada Pérez et al. (2021) have reported an indicative default (parallel to the masculine default) in Spanish HSs in the U.S. Nonetheless, the indicative default is a trend that would not be derived from knowledge of the two grammars, in a similar vein as the argument for the masculine default in Valdés Kroff (2016). Thus, in this paper, we seek to explore CS effects on mood selection in L2ers to test this hypothesis. Although previous research on CS in L2ers does not report differences between intermediate or advanced L2ers and HSs, it does not focus on patterns of CS that are of the type described in this section, i.e., related to the E-language (Toribio 2017).

\subsection{CS Research with L2ers}

While there has been previous research on the formal aspects of CS in simultaneous or early bilinguals, there is little research along those lines in L2ers. Exploring CS in communities where CS takes place seems reasonable and begs the question of what would be gained from exploring it in other types of bilinguals that are not exposed to CS in their communities. Toribio (2001) posited that, in contrast with the knowledge that exists about the well-formedness of CS sentences, little is known about how this syntactic knowledge is developed. L2ers, then, offer good data to explore linguistic development regarding CS. Expanding from work on childhood bilingualism (Köppe and Meisel 1995; Mc Clure 1981; Meisel 1994; Rubin and Toribio 1996), on CS patterns in different types of bilinguals (Aguirre 1978, 1985; Poplack 1980; Valdés 1976; Zentella 1981, 1997), and other L2 studies on CS (Bhatia and Ritchie 1996, 1998; Rakowsky 1989; Toribio et al. 1993), Toribio (2001) explored Spanish L2ers' ability to identify what CS sentences violated the Functional Head Constraint (Belazi et al. 1994). A total of 104 Spanish L2ers of different proficiency levels, classified according to previous years of study, completed an AJT with pairs of sentences contrasting in the switch joint or the directionality of the switch. Sentences included switching at functional and lexical categories, which would be deemed ungrammatical and grammatical, respectively, according to the Functional Head Constraint. Results revealed that proficiency was a predictor, and only the advanced learners made a difference in their ratings of switching at functional vs. lexical sites.

Further work following a similar approach has examined some of these switches, reporting similar proficiency effects. Giancaspro $(2013,2015)$ examined auxiliary and pronoun switches, and although he did not find a proficiency effect among his participants, they were all in upper-level undergraduate courses (equivalent to Toribio's intermediate or advanced speakers). Also examining switches at the pronoun and auxiliary verb, Koronkiewicz (2018) analyzed results from an AJT considering not only proficiency but also CS use. He compared HSs who engaged in CS and were of intermediate-advanced proficiency with groups of L2ers that varied in proficiency and CS: two intermediateadvanced groups that varied in CS use (CSers and non CSers) and two low proficiency 
groups that also varied in their CS use. Interestingly, speaker group differences were not the same in pronoun and auxiliary switches. The L2 group of higher proficiency who reported engaging in CS were indistinguishable from the HSs with auxiliary switches and the closest to the HSs in pronoun switches. The other groups differed depending on CS use and proficiency. CS use, for instance, was significant in the low proficiency groups, but the non-CS group of higher proficiency fell somewhere in between the two low proficiency groups in their ratings. Koronkiewicz (2018), thus, concludes both proficiency and CS use are important in the acquisition of CS. In general, in Giancaspro $(2013,2015)$ and Koronkiewicz (2018), participants showed evidence of acquisition of CS. These results are consistent with Toribio's (2001) hypothesis that once the related grammar is acquired in Spanish, Spanish L2ers can distinguish grammatical and ungrammatical structures.

Koronkiewicz (2018) points out more difficulty with pronoun switches than auxiliary switches, which may indicate that some of the properties of Spanish subject pronouns may not have been fully acquired. In sum, previous research on CS and L2ers seems to indicate that sensitivity to the rules governing CS is a byproduct of grammatical development in the L2 (Giancaspro 2013, 2015; Koronkiewicz 2018; Lipski 2014; Potowski and Bolyanatz 2012; Toribio 2001). Nonetheless, all these research projects focus on the I-language of CS. It is possible that part of CS competence, including acceptable switch junctures, the I-language of CS, is acquired through the acquisition of the syntax of both grammars (Giancaspro 2013, 2015; Guzzardo Tamargo and Dussias 2013; Lipski 2014; Potowski and Bolyanatz 2012; Toribio 2001), while some CS practices may be acquired socially, i.e., those related to the E-language (Torres Cacoullos and Travis 2016). Parafita Couto et al. (2021, p. 17) indicate in their review of several CS structures that have been widely examined, including the masculine default in Det-N switches and the use of bilingual compound verbs, that 'These findings strongly suggest that asymmetries are due to extralinguistic factors, such as community norms, rather than structural properties of the participating languages'. This paper, thus, expands on this idea by examining another structure where Raymond (2012) and Prada Pérez et al. (2021) have found a difference in usage between CS and monolingual modes in Spanish-English bilinguals: mood choice.

In the SLA literature, there is often a distinction between the acquisition of purely grammatical features and variable features (Gudmestad 2013). It is possible to consider the effects of CS on variable phenomena, such as subject pronoun expression, copula choice, or mood choice, as a CS practice that is acquired socially. Considering that Raymond (2012) and Prada Pérez et al. (2021) found a CS effect on mood choice, it is possible that L2ers who are not exposed to CS do not exhibit a CS effect even if they are proficient enough to identify certain switch junctures as ungrammatical. Thus, in this paper we explore the possibility that L2ers and HSs might differ in CS, irrespective of proficiency, so long as we examine variable phenomena, which may depend on exposure to CS. Since the participants in Prada Pérez et al. (2021) completed the same task as the participants in this study, we can compare them. In line with Potowski's (2009, p. 91) statement that 'research comparing second language and native bilingual codeswitching is still in its infancy', we seek to compare Spanish L2ers' CS behavior not in terms of switch junctures but in terms of how CS affects their use of Spanish verbal mood with the patterns reported in Raymond (2012) and Prada Pérez et al. (2021).

In summary, there is a sizeable body of research exploring mood choice in L2ers, some research on CS effects on morphosyntactic structures, and a growing interest in what L2ers can tell us about the acquisition of CS. This paper expands on these by exploring mood choice in Spanish monolingual vs. CS mode in Spanish L2ers.

\section{Present Study}

The present study aims to examine the effect of CS on sensitivity to Spanish verbal mood in Spanish L2ers through two AJTs, one in Spanish only and the other in SpanishEnglish CS, with sentences containing relative clauses. Crucially, we manipulated the verbal mood of the relative clause (indicative vs. subjunctive) and the specificity of the 
relative clause antecedent (specific vs. nonspecific). Our broad research questions are the following:

Research Question 1 (Mood selection): Is sensitivity to indicative and subjunctive moods in relative clauses impacted by specificity of the antecedent?

In previous research on mood selection in relative clauses, difficulty with mood selection is widely attested in Spanish L2ers, especially with English as an L1 (Borgonovo et al. 2006, 2008, 2015). Thus, we expect participants to rate the indicative higher than the subjunctive in contexts where the indicative is expected (i.e., with a specific antecedent). With nonspecific antecedents, however, we do not expect the subjunctive to be preferred or at least to be preferred to the same degree as the indicative in specific relative clauses. This result would be consistent with the indicative extension, in particular, the loss of association with specificity, previously reported in the literature.

Research Question 2 (Language mode): Is L2 sensitivity to mood selection requirements impacted by language mode (i.e., code-switched versus monolingual Spanish sentences)?

Previous research has reported differences in the speech of bilinguals when they are codeswitching, as opposed to when they are in Spanish monolingual mode, an effect that we refer to here as a CS effect. In particular, previous research has identified a CS effect in subject expression (e.g., Prada Pérez 2018; Toribio 2004; Torres Cacoullos and Travis 2011, 2016), increased indeterminacy in copula selection in Spanish-English Cuban HSs (Prada Pérez and Hernández 2017), and in mood choice in nominal and adjectival clauses (Prada Pérez et al. 2021; Raymond 2012). To the best of our knowledge, there is no comparable previous research with L2ers. Thus, we adhere to the null hypothesis and anticipate no CS effect. Assuming that these CS preferences are not derived from grammatical knowledge in each of the languages and that exposure to the CS community is necessary (Torres Cacoullos and Travis 2018), no CS effect is expected for L2ers, particularly since our participants do not seem to interact with a bilingual speech community.

\subsection{Participants}

A total of 20 Spanish L2ers (14 females; mean age 20.9 years; range 20-22) were recruited from a large research institution in the U.S., who, at the time of data collection, were enrolled in third and fourth year Spanish courses and who had acquired Spanish after the age of 11 and in a classroom context. Learners from third and fourth year classes were recruited, as these individuals had already met the basic language requirements from lower-level courses and had likely already been taught about the subjunctive in relative clauses (which, at the institution, is typically taught in the third semester). Informed consent was obtained from all participants involved in the study.

The participants were born in the U.S., except for three who were born abroad (nonSpanish speaking countries) but moved to the U.S. before age 6. Two participants reported having studied a third language, Portuguese and Chinese, respectively, and one participant reported also being a native speaker of Haitian Creole. All the participants learned Spanish in school, with 13 of them being first exposed to it in middle/high school (ages 11-15), 5 in elementary school (ages 6-10), and 1 in college at age 18. When they were offered Gumperz' (1982) definition of CS, an example of what would be CS vs. loanwords (e.g., lunchear 'to eat lunch,' parquear 'to park', chompear 'to chomp'), 11 participants reported engaging in CS. With our question being rather vague, we are unable to ascertain whether participants who reported CS indeed engaged in CS or were exposed to it in the community or were referring of switches for a lexical gap (cf. Koronkiewicz 2018, for a methodology to better attain this information from participants). Thus, this predictor was not included in the main analyses.

Results from an independent measure of proficiency (a 50-item section of the DELE typically used in the field, Montrul and Slabakova 2003) indicated that 1 participant scored above 40 and was classified as advanced, 10 scored between 30 and 40 and were classified 
as intermediate, and 9 scored below 30 and were classified as of low proficiency (all participants: $M=29.1(11-44), S D: 8.0)$. For the analyses, proficiency was included as a continuous variable based on mean-centered scores.

\subsection{Materials}

In addition to the proficiency measure and the language background questionnaire, participants completed two written AJTs, depending on language mode: one in Spanish and one in Spanish-English CS, administered via the online platform Qualtrics. Participants were instructed to read and judge the acceptability of sentences on a 4-point Likert scale ( 1 = totally unacceptable; 2 = unacceptable; 3 = acceptable; 4 = totally acceptable), according to their intuitions. Specifically, they were told to judge the sentences in terms of how they are accepted 'under normal circumstances' and not based on whether they conform to standard usage of grammar. Target sentences were manipulated for mood (half of the embedded verbs were in the subjunctive mood and the other half were in the indicative) and specificity of the antecedent (half of the target sentences contained a definite/specific antecedent, via the use of specificity markers, and the other half contained a negative antecedent). Participants completed the AJT in two modes: a Spanish-only and a CS one, distributed on separate sessions. All target sentences were controlled for tense of the subordinate verb (all were in the present tense) and the relativizing pronoun (always que). Across conditions there were similar ratios of regular and irregular verb forms (11 regular and 13 irregular in the Spanish-only conditions and 9 regular and 15 irregular in the CS conditions) (Table 1). The verbs used in the relative clause were controlled for frequency across language mode conditions, based on frequency rankings from Davies (2006). A Wilcoxon-Mann-Whitney test revealed there were no significant differences in the verb frequency used for Spanish-only ( $M d n$ : 92) versus the codeswitching sentences (Mdn: 57) $(W=244.5, p=0.667)$. Experimental stimuli are included in the Supplementary Material.

Table 1. List of verbs used in the materials (repetitions in parentheses).

\begin{tabular}{|c|c|c|c|}
\hline \multicolumn{2}{|c|}{ Spanish-Only Condition } & \multicolumn{2}{|l|}{ CS Condition } \\
\hline $\begin{array}{l}\text { Regular } \\
\text { apoyar 'to support' } \\
\text { ayudar 'to help' } \\
\text { gustar (x2) 'to like' } \\
\text { hablar ( } \mathrm{x} 2) \text { 'to talk' } \\
\text { interesar 'to interest' } \\
\text { llamar 'to call' } \\
\text { reparar 'to repair' } \\
\text { roncar 'to snore' } \\
\text { tratar de 'to be about' }\end{array}$ & $\begin{array}{l}\text { Irregular } \\
\text { costar 'to cost' } \\
\text { estar 'to be' } \\
\text { explicar 'to explain' } \\
\text { poder (x2) 'to be able' } \\
\text { saber }(\mathrm{x} 3) \text { 'to know' } \\
\text { ser }(\mathrm{x} 2) \text { 'to be' } \\
\text { tener }(\mathrm{x} 3) \text { 'to have' }\end{array}$ & $\begin{array}{l}\text { Regular } \\
\text { correr 'to run' } \\
\text { gustar (x2) 'to like' } \\
\text { hablar 'to talk' } \\
\text { ladrar 'to bark' } \\
\text { llevar 'to carry' } \\
\text { vender 'to sell' } \\
\text { viajar 'to travel' } \\
\text { vivir 'to live' }\end{array}$ & $\begin{array}{l}\text { Irregular } \\
\text { explicar 'to explain' } \\
\text { hacer 'to make' } \\
\text { poder 'to be able' } \\
\text { querer }(\mathrm{x} 2) \text { 'to want' } \\
\text { saber }(\mathrm{x} 2) \text { 'to know' } \\
\text { sentir 'to feel' } \\
\text { ser }(\mathrm{x} 4) \text { 'to be' } \\
\text { servir 'to serve' } \\
\text { tener }(\mathrm{x} 2) \text { 'to have' }\end{array}$ \\
\hline
\end{tabular}

There were eight experimental conditions in total: four in Spanish-only (monolingual mode) and four in English-Spanish CS (bilingual mode), where the matrix clause was in English and the relative clause was in Spanish. Examples of the four CS conditions are listed below. Comparable sentences in Spanish-only were presented in the first session.

(3) CS conditions

Condition 5. Codeswitched sentences, Specific antecedent, Indicative mood

This summer I am going to visit my friend [que vive en California].

This summer I am going to visit my friend who lives-IND in California.

'This summer I'm going to visit my friend who lives in California.'

*Condition 6. Codeswitched sentences, Nonspecific antecedent (Nadie/Nada/Ninguno), Indicative mood

Stephanie doesn't know anybodyhere [que es una buena persona].

Stephanie doesn't know anybodyhere who is-IND a good person.

'Stephanie doesn't know anybody here who is a good person.' 


\section{*Condition 7. Codeswitched sentences, Specific antecedent, Subjunctive mood}

My best friend Lauren

My best friend Lauren

is a person [que me quiera

is a person who me loves-SUBJ por lo que soy].

for what am.

'My best friend Lauren is a person who loves me for what I am.'

Condition 8. Codeswitched sentences, Nonspecific antecedent (Nadie/Nada/Ninguno), Subjunctive mood

In the book, there is no chapter [que explique la velocidad
In the book there is no chapter that explains-SUBJ the speed
'In the book, there is no chapter that explains the speed of light.'

Conditions 1-4 were entirely in Spanish, and conditions 5-8 contained sentences that were code-switched between English and Spanish. Participants completed the Spanish-only (monolingual mode) AJT first and were provided with the link to the CS (bilingual mode) AJT at least $24 \mathrm{~h}$ after taking the first survey. Lastly, they were not allowed to go back and change their responses. Participants were sent experiment links to their email and, thus, were able to complete the surveys from their own laptop or mobile devices. ${ }^{1}$

Each condition contained 6 items, resulting in a total of 48 target sentences. The task additionally presented 48 filler sentences ( 24 monolingual Spanish and 24 Spanish/English code-switched), none of which contained a relative clause, but which contained varying instances of the subjunctive and indicative in nominal and adverbial clauses to not restrict the presentation of the subjunctive to experimental conditions only. The target sentences and fillers in each task were presented in a randomized order generated by Qualtrics.

\subsection{Results}

Survey ratings were analyzed in $R$ ( $R$ Core Team 2017) by fitting cumulative link mixed effects models with a specified probit link function (clmm function in package ordinal; Christensen 2019). The probit link function models the z-score (i.e., changes in standard deviation units) of the probability of increasing the rating by 1 on the Likert scale (e.g., rating a sentence as 4 over 3, or as 3 over 2, etc.), and thresholds between each Likert value were set to flexible (which is also the default in $\mathrm{clmm}$ ), given that ratings may not be treated equally across the scale. For example, on a 4-point Likert scale, individuals may not perceive the difference between a 3 and a 4 ('Acceptable' and 'Totally acceptable', respectively) the same as that between a 2 and a 3 ('Unacceptable' and 'Acceptable'). In interpreting the model, the coefficients represent the effect of predictors on the probability that the ratings will increase and not directly on the ratings per se.

Model fitting began by including a maximal fixed-effects structure (i.e., all main effects and interaction terms), given the interest of the interaction between Mood, Mode, and Specificity. Fixed effects were dummy coded and included Mood (Indicative [reference], Subjunctive), Mode (Spanish-only [reference], Codeswitched), and Specificity (Specific [reference], Nonspecific). Random intercepts of Participant and Item were also included. Regression coefficients represent whether a particular level of one of the factors differs significantly from the reference level (e.g., specific antecedents vs. nonspecific antecedents, in sentences that are Spanish-only and in the indicative mood). For testing main effects, we used log-likelihood ratio tests and compared nested models with and without the factor of interest (Meteyard and Davies 2020), and comparisons across conditions were analyzed using emmeans (Lenth 2020). The final equation is provided below:

$\operatorname{clmm}\left(\right.$ Rating $\sim \operatorname{Mood}^{*}$ Mode*Spec $+(1 \mid$ Participant $)+(1 \mid$ Item $)$, data $=$ L2, link = 'probit' $)$

Mean ratings per condition are shown in Figure 1. The analysis revealed significant effects of Mood $\left(\chi^{2}(4)=57.289, p<0.001\right)$, Mode $\left(\chi^{2}(4)=26.560, p<0.001\right)$, and Specificity $\left(\chi^{2}(4)=24.233, p<0.001\right)$, as well as a significant interaction of Mood $\times$ Specificity $\left(\chi^{2}(2)=23.272, p<0.001\right)$ and $\operatorname{Mood} \times \operatorname{Mode}\left(\chi^{2}(2)=18.116, p<0.001\right)$, but not Mode $\times$ Specificity $\left(\chi^{2}(2)=2.618, p=0.270\right)$ or Mood $\times$ Mode $\times$ Specificity $\left(\chi^{2}(1)=1.753, p=0.186\right)$. 
The interaction between Mood and Specificity revealed that sentences in the indicative mood were rated higher with specific than nonspecific antecedents $(\beta=0.536, S E=0.126$, $z=4.270, p<0.001)$, while the subjunctive mood was rated higher with nonspecific than specific antecedents $(\beta=0.390, S E=0.123, z=3.176, p=0.002)$. These patterns are consistent with specificity requirements for verbal mood in Spanish. Comparisons of verbal moods revealed that the indicative mood was rated higher than the subjunctive with specific antecedents $(\beta=1.142, S E=0.128, z=8.953, p<0.001)$, while this preference was only marginal with nonspecific antecedents $(\beta=0.215, S E=0.123, z=1.746, p=0.081)$. Crucially, the lack of a three-way interaction among Mood $\times$ Mode $\times$ Specificity suggests that L2ers sensitivity to verbal mood and specificity requirements is not affected by whether sentences are presented in Spanish-only or in Spanish-English CS. The final model is presented in Table 2.

\section{Mean Ratings per Condition}

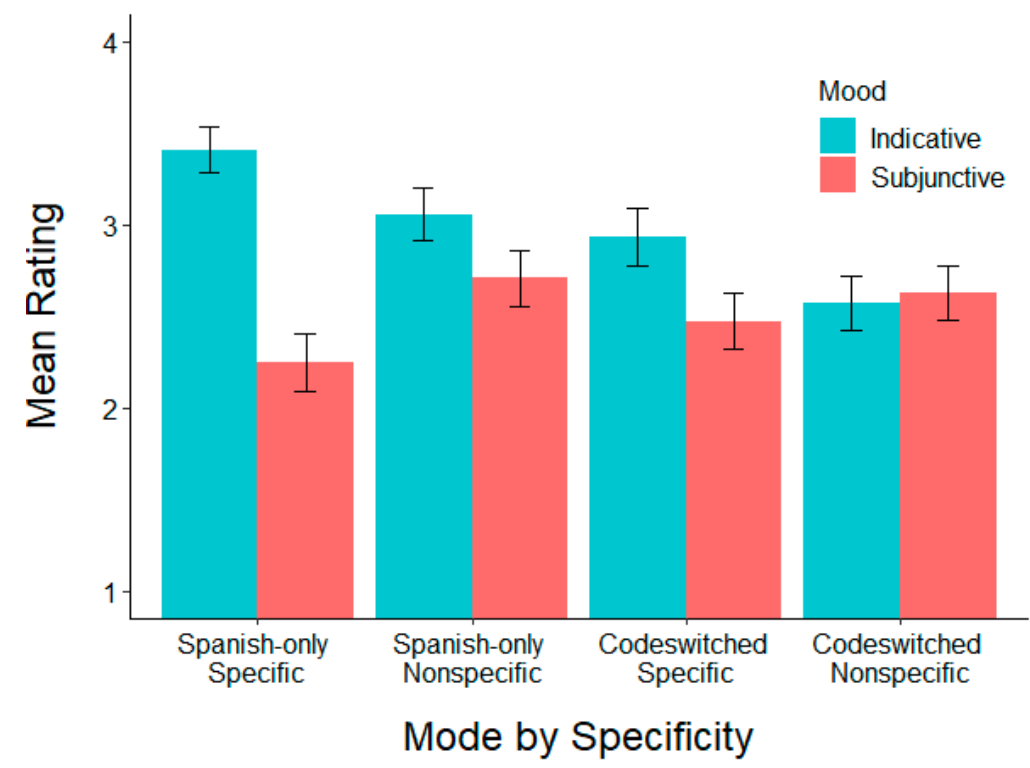

Figure 1. Mean ratings per condition with $95 \%$ confidence interval bars.

Table 2. Final model of speaker ratings, without proficiency (reference level is Spanish-only, Indicative mood, Specific antecedents).

\begin{tabular}{lllll}
\hline Fixed Effects & & & & \\
\hline & $\beta$ & $S E$ & $z$ & $p$ \\
Mood (Sub) & -1.652 & 0.182 & -9.067 & $<0.001$ \\
Mode (CS) & -0.742 & 0.180 & -4.124 & $<0.001$ \\
Specificity (Non) & -0.572 & 0.180 & -3.185 & 0.001 \\
Mood $\times$ Mode (Sub, CS) & 1.020 & 0.250 & 4.078 & $<0.001$ \\
Mood $\times$ Spec (Sub, Non) & 1.160 & 0.251 & 4.629 & $<0.001$ \\
Mode $\times$ Spec (CS, Non) & 0.071 & 0.250 & 0.285 & 0.776 \\
Mood $\times$ Mode $\times$ Spec (Sub, CS, Non) & -0.467 & 0.350 & -1.333 & 0.182 \\
\hline Random Effects & & & & \\
\hline & Variance & & S.D. & \\
\hline Item & 0.032 & & 0.178 & \\
Subject & 0.067 & & & \\
\hline
\end{tabular}

Model fit (LL): -1112.52 .

We also explored the role of proficiency by incorporating it as a factor within a maximal fixed-effects structure. Proficiency scores were mean-centered, and data analyses followed 
the same methods as the analysis without proficiency. The final model is presented below, and final model output is presented in Table 3:

$\operatorname{clmm}\left(\right.$ Rating $\sim$ Mood $^{*}$ Mode $^{*}$ Spec$^{*}$ Proficiency $+(1 \mid$ Participant $)+(1 \mid$ Item $)$, data $=$ L2, link = 'probit' $)$

Table 3. Final model of speaker ratings, with proficiency (reference level is Spanish-only, Indicative mood, Specific antecedents, proficiency centered at average).

\begin{tabular}{lllll}
\hline Fixed Effects & & & & \\
\hline & $\beta$ & $S E$ & $z$ & $p$ \\
Mood (Sub) & -1.704 & 0.187 & -9.099 & $<0.001$ \\
Mode (CS) & -0.773 & 0.185 & -4.178 & $<0.001$ \\
Specificity (Non) & -0.606 & 0.184 & -3.285 & 0.001 \\
Proficiency & 0.059 & 0.015 & 4.003 & $<0.001$ \\
Mood $\times$ Mode (Sub, CS) & 1.057 & 0.257 & 4.119 & $<0.001$ \\
Mood $\times$ Spec (Sub, Non) & 1.206 & 0.257 & 4.694 & $<0.001$ \\
Mode $\times$ Spec (CS, Non) & 0.092 & 0.256 & 0.360 & 0.719 \\
Mood $\times$ Proficiency & -0.080 & 0.019 & -4.313 & $<0.001$ \\
Mode $\times$ Proficiency & 0.005 & 0.019 & 0.254 & 0.800 \\
Specificity $\times$ Proficiency & -0.053 & 0.019 & -2.852 & 0.004 \\
Mood $\times$ Mode $\times$ Spec (Sub, CS, Non) & -0.497 & 0.359 & -1.385 & 0.166 \\
Mood $\times$ Mode $\times$ Proficiency & 0.039 & 0.026 & 1.484 & 0.138 \\
Mood $\times$ Spec $\times$ Proficiency & 0.075 & 0.026 & 2.894 & 0.004 \\
Mode $\times$ Spec $\times$ Proficiency & 0.015 & 0.026 & 0.583 & 0.560 \\
Mood $\times$ Mode $\times$ Spec $\times$ Proficiency (Sub, CS, Non) & -0.031 & 0.036 & -0.862 & 0.389 \\
\hline Random Effects & & & & \\
\hline & Variance & & S.D. & \\
\hline Item & 0.036 & & 0.189 & \\
Subject & 0.040 & & 0.199 & \\
\hline Mode $($ LL) -109185. & & &
\end{tabular}

Model fit (LL): -1091.85 .

We report results here only for terms involving Proficiency. The analysis revealed that there was a significant effect of Proficiency $\left(\chi^{2}(8)=41.324, p<0.001\right)$, Mood $\times$ Proficiency $\left(\chi^{2}(4)=23.883, p<0.001\right)$, Specificity $\times$ Proficiency $\left(\chi^{2}(4)=13.984, p=0.007\right)$, and Mood $\times$ Specificity $\times$ Proficiency $\left(\chi^{2}(2)=11.211, p=0.004\right)$, a marginal interaction of Mode $\times$ Proficiency $\left(\chi^{2}(4)=9.267, p=0.055\right)$, and no significant effects of Mode $\times$ Specificity $\times$ Proficiency $\left(\chi^{2}(2)=0.746, p=0.689\right)$, Mood $\times$ Mode $\times$ Proficiency $\left(\chi^{2}(2)=2.283\right.$, $p=0.319)$, or Mood $\times$ Mode $\times$ Specificity $\times$ Proficiency $\left(\chi^{2}(1)=0.744, p=0.389\right)$. The lack of a significant four-way interaction suggests that proficiency did not modulate ratings differently across conditions based on language mode. However, the interaction of Mood $\times$ Specificity $\times$ Proficiency suggests that sensitivity to verbal mood and specificity constraints may differ based on proficiency. Specifically, for a person of average proficiency, a 1 unit increase in proficiency was associated with higher rating likelihood for sentences with specific antecedents and the indicative $\operatorname{mood}(\beta=0.061, S E=0.011, z=5.526, p<0.001)$ but not for any other conditions ( $p^{\prime}$ s $\left.>0.145\right)$. To examine the simple effects of Mood $\times$ Specificity at different proficiency levels, proficiency scores were recentered based on quartiles (Q1: 25th percentile on the lower end; Q3: 75th percentile on the higher end). This revealed that L2ers rated the indicative mood higher with specific than nonspecific antecedents, and this distinction increases with proficiency (Q1: $\beta=0.362, S E=0.139$, $z=2.599, p=0.009$; Q3: $\beta=0.782, S E=0.146, z=5.374, p<0.001$ ). For the subjunctive mood, participants were more likely to rate sentences higher with nonspecific than specific antecedents, and this also increases with proficiency $(\mathrm{Q} 1: \beta=0.339, S E=0.138, z=2.461$, $p=0.014$; Q3: $\beta=0.465, S E=0.140, z=3.313, p=0.001)$. Additionally, verbal $\operatorname{mood}$ comparisons show that with specific antecedents, participants rated the indicative higher than the subjunctive (Q1: $\beta=0.911, S E=0.140, z=6.487, p<0.001$; Q3: $\beta=1.472, S E=0.148$, $z=9.936, p<0.001)$. In contrast, for nonspecific antecedents, there was no difference 
between the indicative and subjunctive ratings at either lower or higher proficiency levels (Q1: $\beta=0.210, S E=0.138, z=1.526, p=0.127$; Q3: $\beta=0.225, S E=0.140, z=1.604$, $p=0.109$ ). Figure 2 depicts the relationship between average ratings per condition and proficiency scores; for transparency and reader's convenience, we show the trends for both Spanish-only and Codeswitched sentences.

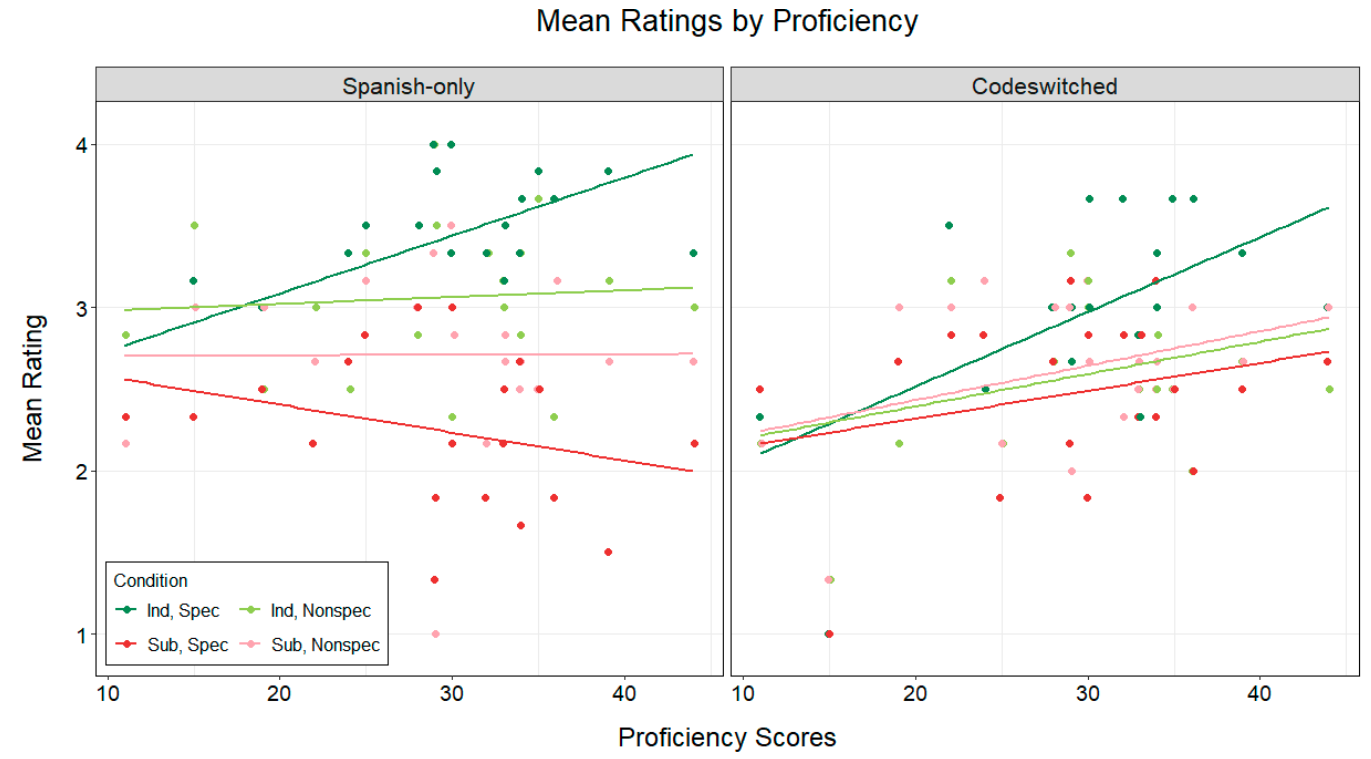

Figure 2. Proficiency and mean ratings per condition.

The trends reported in the results are summarized in Table 4.

Table 4. Summary of results.

\begin{tabular}{lllll}
\hline Effect & Monolingual and CS Sentences & \\
\hline \multirow{2}{*}{ Mood } & Specific & Nonspecific & \\
\cline { 2 - 5 } & Ind $>$ sub & \multicolumn{2}{l}{ Ind marginally $>$ sub } \\
\hline \multirow{2}{*}{ Specificity } & Indicative & \multicolumn{2}{l}{ Subjunctive } & \\
\cline { 2 - 5 } & Spec $>$ nonspec & Nonspec $>$ spec & \\
\hline \multirow{2}{*}{ Proficiency score } & Ind + Spec & Ind + Nonspec & Subj + Spec & Subj + Nonspec \\
\cline { 2 - 5 } & Sig (expected direction) & n.s. & n.s & n.s. \\
\hline
\end{tabular}

\section{Discussion}

In this section, we return to each of the research questions considering the results. The first question inquired about mood selection in Spanish L2ers. Previous research on mood selection and use by L2ers in generative and variationist traditions report difficulty with mood distinctions in certain uses of the subjunctive, including relative clauses. We postulated that participants would rate the indicative higher than the subjunctive in contexts where the indicative is expected (i.e., with a specific antecedent). With nonspecific antecedents, however, we did not expect the subjunctive to be preferred or at least to be preferred to the same degree as the indicative in specific relative clauses. This result would be consistent with the indicative extension previously reported in the literature and was indeed attested in our data. Participants rated sentences in the indicative verb form higher than in the subjunctive verb form with specific antecedents, while the preference for the indicative with nonspecific antecedents was only marginally significant. The specificity effect is significant for both indicative and subjunctive sentences but was modulated by proficiency in the case of indicative sentences with specific antecedents. Thus, it seems that the association of specificity and mood was strong in these participants in general. 
In line with previous research, though, the association between indicative and specificity was acquired at higher levels of proficiency (Borgonovo et al. 2006, 2008, 2015), while the association of the subjunctive with nonspecificity was not as strong and did not change with proficiency.

The results are suggestive of the progression in the acquisition of mood alternation in Spanish restrictive relative clauses, which is consistent with the previous literature. Specifically, difficulty is identified with restricting the acceptability of the indicative to specific contexts; that is, there is difficulty with rejecting the indicative in nonspecific contexts. This is attested in our results where the indicative was rated marginally higher than the subjunctive in nonspecific contexts. Additionally, our data show that there were no proficiency effects for mood selection in nonspecific contexts. Thus, the indicative extension, where it was accepted almost as much as the subjunctive in the context where the subjunctive is prescribed, was present across proficiency levels. In contrast, there was a proficiency effect in the rating of the indicative with specific antecedents, where, while all groups accepted the indicative with specific antecedents, the acceptance rate was higher at higher levels of proficiency.

Our results reveal some interesting trends with respect to the effect of proficiency, where, as proficiency increases, participants are more likely to assign a higher rating to sentences in the indicative mood with a specific antecedent. Overall, results indicate that even at lower levels of proficiency, speakers have associated the indicative with specificity, since the ratings for indicative were higher with specific than with nonspecific antecedents, and the subjunctive with nonspecificity, since the ratings for the subjunctive were higher with nonspecific than with specific antecedents. Additionally, in specific contexts, the rating of the indicative was significantly higher than that of the subjunctive, and this was modulated by proficiency due to the indicative mood being rated higher as proficiency increased. Thus, it seems that learners were rather target-like in their knowledge, and with respect to the indicative with specific contexts, their judgments were becoming more determinate. However, the indicative was rated similarly to the subjunctive in nonspecific contexts, and this did not improve with proficiency. In summary, the L2ers seemed to have established semantic associations for mood distinctions in Spanish, and while the acceptability of the indicative mood in specific contexts becomes more established with proficiency, the indeterminacy with mood in nonspecific contexts remains across proficiency levels.

For our second research question, which investigated the effects of CS on mood selection, we expected to observe no effect in L2ers. There was no CS interaction with mood and specificity in this group. This is a somewhat unexpected result, given previous CS studies on I-language aspects of CS showing that HSs and L2ers have similar constraints (e.g., Koronkiewicz 2018 and works cited therein). This study, however, is unprecedented in the literature in that it does not analyze L2 CS competence related to I-language (all switch junctures were acceptable according to the literature) but the effects that (lack of) exposure to CS has on certain grammatical aspects of Spanish, an E-language aspect, specifically where the distribution (indicative vs. subjunctive) is not categorical in monolingual varieties. It is important to recall that Prada Pérez et al. (2021) and Raymond (2012) reported Spanish HSs do not associate the subjunctive with nonspecificity in CS. Thus, while L2ers with higher proficiency in Spanish are predicted to associate the subjunctive with nonspecificity more than those of lower proficiency, those with more exposure to CS would be using it less, in parallel to the use in the bilingual CS community. Here, L2ers showed a distinction between specific and nonspecific antecedents for both the indicative and the subjunctive moods, but this was not modulated by language mode. Additionally, this sensitivity to antecedent specificity and verbal mood increased with proficiency. In contrast, Spanish HSs in Prada Pérez et al. (2021) showed a specificity distinction for the subjunctive in Spanish-only sentences, but this was lost in the CS sentences. Our participants were not part of the CS community, and they did not parallel the results in Prada Pérez et al. (2021), where the same task and materials were used. In this way, it is consistent with the proposal 
by Torres Cacoullos and Travis (2018) that exposure to CS in the community is necessary for speakers to acquire CS patterns, particularly as they involve the E-language.

These results are suggestive of differences in the development of CS competence and CS practices with respect to variable linguistic structures, such as mood choice in polarity contexts (Viner 2016; van Osch and Sleeman 2018). Nonetheless, with the limited number of participants and the metalinguistic nature of the task, these results invite further research to test this suggestion. The participants may have perceived the task, given its metalinguistic nature, as assessing their grammatical knowledge. That is, the task type, being a written offline task, may have further contributed to this group's interpretation of the task as a Spanish grammar task. Thus, testing other structures where CS effects have been attested for HSs, such as the gender of the determiner in Determiner-Noun switches, and obtaining data from corpora or elicited production are necessary. Nonetheless, this result is not isolated in the CS literature. In their study of VOTs, Bullock et al. (2006) observe that some highly advanced L2ers exaggerate low VOTs in Spanish in CS, in comparison with their reading of monolingual sentences.

\section{Conclusions and Future Directions}

In this paper, we examined mood selection in Spanish L2ers. We concluded that Spanish L2ers make a mood distinction in restrictive relative clauses, as they treated specific and nonspecific antecedents differently with respect to the preferred mood form. We did find, however, evidence of a different use of the subjunctive mood than the one prescribed, as there was no clear preference for the subjunctive over the indicative with nonspecific subjects. This weakening in the preference for the subjunctive in nonspecific contexts parallels the results attested in previous work (Borgonovo et al. 2006, 2008, 2015; Silva-Corvalán 1994, among others). A proficiency effect was found where the rating for the indicative mood in specific contexts was significantly higher at higher levels of proficiency. This was a quantitative difference, though, since at all levels they rated the indicative higher than the subjunctive with specific antecedents.

More central to the purpose of this paper was the contrast between the speaker bilingual modes (Spanish-only vs. CS conditions). In the recent focus on CS effects on variable phenomena in the speech of Spanish HSs, an E-language approach to CS, there is evidence of resorting to default forms in CS (e.g., higher use of overt pronominal subjects, copula choice weakening in comparison with monolingual varieties of Spanish). In Prada Pérez et al. (2021), HSs associated the subjunctive with nonspecificity in monolingual mode, but this association was not evident in CS. Spanish L2ers in this study did not show evidence of a CS effect; thus, these hypotheses seem to be applicable to those speakers who have acquired Spanish in the home and in the specific sociolinguistic context of Spanish HSs in the U.S.

Previous research on CS effects on morphosyntactic features has not included L2ers. Our data indicate differences between HSs and L2ers with respect to CS effects on mood selection in Spanish. Crucially, HSs exhibit a simplification in CS, where the association of nonspecificity of the subjunctive is not present in CS, while L2ers do not exhibit such simplification. Since HSs in Raymond (2012) and Prada Pérez et al. (2021) are likely exposed to and engage in CS, the data can be interpreted as indicative of the different patterns for mood selection encountered in their community when they are in monolingual mode vs. when they are engaging in CS, an aspect related to usage and E-language. CS in the classroom is limited, since it is stigmatized, although it is likely that there is some CS (Koronkiewicz 2018). It is not clear, however, whether the CS taking place in the community and that taking place in the classroom are comparable. If the CS that our participants have been exposed to is different, it is possible that they were evaluating the CS sentences in a linear way, that is, in sections: evaluating the English fragment with their English grammar and the Spanish fragment with their Spanish grammar. HSs in Raymond (2012) and Prada Pérez et al. (2021), on the other hand, could have approached the task where they were evaluating the sentence as a whole, where an English noun in the antecedent does not 
necessarily select for a subjunctive or an indicative verb form in the embedded clause. This is a similar argument to the one offered for the use of the analogical criterion vs. the masculine default in Determiner-Noun CS (e.g., Denbaum and Prada Pérez 2020; Valdés Kroff 2016). Thus, it seems reasonable that our participants were evaluating mood choice in the relative clause against their Spanish grammar, independently of language mode. It is important to point out that these participants and those in Prada Pérez et al. (2021) were all English-dominant speakers who differed in exposure to CS and L1. In Munarriz-Ibarrola et al. (2021), Basque L1 and Spanish L1 bilinguals were sensitive to the analogical criterion and the phonological criterion in the gender assignment of the determiner in Determiner-Noun switches depending on their L1. Thus, the L1 difference could also explain differences between our data and that in Prada Pérez et al. (2021).

There are a couple limitations and potential future directions for this study. First, participants were allowed to complete the surveys at home; thus, some individuals completed the task much faster/slower than others, which may have given rise to unintended differences in how participants engaged with the task. One potential future direction would be to control the experimental environment and to have participants complete the surveys in a lab setting. Additionally, the study would benefit from examining a Spanish-English bilingual corpus to see how often relative clause switches occur in naturalistic speech. Finally, the study has implications for language researchers and educators. In particular, mood distinction in adjectival clauses has been shown to be particularly challenging for Spanish L2ers, and Borgonovo et al. (2015) found that neither advanced nor intermediate L2ers distinguished between the indicative and the subjunctive for negated nonspecific relative clauses. The data from the present study suggest that L2ers also do not show sensitivity to the mood distinction in such clauses, but are nonetheless sensitive to the semantic distinctions (antecedent specificity) for both moods. Although task differences between the studies should be considered (Borgonovo et al. 2015 used a contextualized acceptability judgment task with three items per condition, whereas the present study involved acceptability judgments with isolated sentences and six items per condition), future research and discussion is warranted to clarify overall how evaluation of mood distinctions versus antecedent specificity distinctions can shed light on assessing learner knowledge of the Spanish subjunctive. Findings of such research has implications for how the subjunctive in relative clauses may be taught, particularly with respect to the notion of (non)specificity and how this may be encoded or deduced from both within a single sentence or a larger discourse context.

Supplementary Materials: The following are available online at https:/ / www.mdpi.com/article/10 .3390/languages6040200/s1.

Author Contributions: Conceptualization, N.F., A.d.P.P. and L.K.; Data curation, N.F. and L.K.; Formal analysis, N.F. and A.d.P.P.; Methodology, N.F. and A.d.P.P.; Project administration, N.F.; Writing-original draft, N.F. and A.d.P.P.; writing-review and editing, N.F. and A.d.P.P. All authors have read and agreed to the published version of the manuscript.

Funding: This research was funded by National Institute on Deafness and Other Communication Disorders, grant number T32-DC000052.

Institutional Review Board Statement: The study was conducted according to the guidelines of the Declaration of Helsinki, and approved by the Institutional Review Board (or Ethics Committee) of University of Florida (protocol code 2014-U-0227, approved 5 March 2014).

Informed Consent Statement: Informed consent was obtained from all subjects involved in the study.

Data Availability Statement: The data presented in this study are available on request from the corresponding author. The data are not publicly available due to ethical restrictions.

Acknowledgments: We would like to thank Charlie Redmon (Oxford University) for his support with the statistical analysis. 
Conflicts of Interest: The authors declare no conflict of interest.

\section{Note}

1 This study was carried out prior to the COVID-19 pandemic.

\section{References}

Aguirre, Adalberto, Jr. 1978. An Experimental Sociolinguistic Study of Chicano Bilingualism. San Francisco: R\&E Research.

Aguirre, Adalberto, Jr. 1985. An experimental study of code alternation. International Journal of the Sociology of Language 53: 59-82. [CrossRef]

Balam, Osmer, Ana de Prada Pérez, and Dámaris Mayans. 2014. A congruence approach to the study of bilingual compound verbs in Northern Belize contact Spanish. Spanish in Context 11: 243-65. [CrossRef]

Balam, Osmer. 2016. Semantic Categories and Gender Assignment in Contact Spanish: Type of Code-Switching and its Relevance to Linguistic Outcomes. Journal of Language Contact 9: 1-31. [CrossRef]

Balam, Osmer, María del Carmen Parafita Couto, and Hans Stadthagen-González. 2020. Bilingual verbs in three Spanish/English code-switching communities. The International Journal of Bilingualism 24: 952-67. [CrossRef]

Beatty-Martínez, Anne L., and Paola E. Dussias. 2017. Bilingual experience shapes language processing: Evidence from codeswitching. Journal of Memory and Language 95: 173-89. [CrossRef]

Beatty-Martínez, Anne L., and Paola E. Dussias. 2019. Revisiting masculine and feminine grammatical gender in Spanish: Linguistic, psycholinguistic, and neurolinguistic evidence. Frontiers in Psychology 10: 751. [CrossRef] [PubMed]

Belazi, Hedi M., Edward J. Rubin, and Almeida J. Toribio. 1994. Code-switching and X-bar theory: The Functional Head Constraint. Linguistic Inquiry 25: 221-37.

Bhatia, Tej K., and William C. Ritchie. 1996. Bilingual language mixing, universal grammar, and second language acquisition. In The Handbook of Second Language Acquisition. Edited by W. Ritchie and T. Bathia. New York: Academic Press, pp. 627-88.

Bhatia, Tej K., and William C. Ritchie. 1998. Language mixing and second language acquisition: Some issues and perspectives. In The Development of Second Language Grammars: A Generative Approach. Edited by Elaine C. Klein and Gita Martohardjono. Amsterdam: Benjamins, pp. 241-65.

Blokzijl, Jeffrey, Margaret Deuchar, and M. Carmen Parafita Couto. 2017. Determiner asymmetry in mixed nominal constructions: The role of grammatical factors in data from Miami and Nicaragua. Languages 2: 20. [CrossRef]

Borgonovo, Claudia, and Philippe Prévost. 2003. Knowledge of polarity subjunctive in L2 Spanish. In Proceedings of the 27th Annual Boston University Conference on Language Development. Edited by Barbara Beachley, Amanda Brown and Frances Conlin. Somerville: Cascadilla Proceedings Project, pp. 150-61.

Borgonovo, Claudia, Joyce Bruhn de Garavito, and Philippe Prévost. 2006. Is the semantics/syntax interface vulnerable in L2 acquisition? Focus on mood distinctions clauses in L2 Spanish. In The Acquisition of Syntax in Romance Languages. Edited by Vincent Torrens and Linda. Escobar. Amsterdam: John Benjamins, pp. 353-69.

Borgonovo, Claudia, Joyce Bruhn de Garavito, and Philippe. Prévost. 2008. Methodological issues in the L2 acquisition of a syntax/semantics phenomenon: How to assess L2 knowledge of mood in Spanish relative clauses. In Selected Proceedings of the 10th Hispanic Linguistics Symposium. Edited by Joyce Bruhn de Garavito and Elena Valenzuela. Somerville: Cascadilla Proceedings Project, pp. 13-24.

Borgonovo, Claudia, Joyce Bruhn de Garavito, and Philippe Prévost. 2015. Mood selection in relative clauses: Interfaces and variability. Studies in Second Language Acquisition 37: 33-69. [CrossRef]

Bullock, Barbara, Almeida J. Toribio, Verónica González, and Amanda Dalola. 2006. Language dominance and performance outcomes in bilingual pronunciation. In Proceedings of the 8th Generative Approaches to Second Language Acquisition Conference (GASLA 2006). Edited by Mary Grantham O'Brien, Christine Shea and John Archibald. Somerville: Cascadilla Proceedings Project, pp. 9-16.

Christensen, Rune Haubo B. 2019. Ordinal—Regression Models for Ordinal Data. R Package Version 2019-12-10. Available online: https:/ /CRAN.R-project.org/package=ordinal (accessed on 1 May 2021).

Collentine, Joseph. 1995. The development of complex syntax and mood selection abilities by intermediate-level learners of Spanish. Hispania 78: 122-35. [CrossRef]

Collentine, Joseph. 2010. The acquisition and teaching of the Spanish subjunctive: An update on current findings. Hispania 93: 39-51.

Davies, Mark. 2006. A Frequency Dictionary of Spanish: Core Vocabulary for Learners. New York: Routledge.

Denbaum, Nofiya, and Ana de Prada Pérez. 2020. How do Spanish heritage speakers in the US assign gender to English nouns in Spanish-English code-switching? The effect of noun canonicity and codeswitcher type. Linguistic Approaches to Bilingualism 11: 846-72. [CrossRef]

Deuchar, M. 2020. Code-Switching in Linguistics: A Position Paper. Languages 5: 22. [CrossRef]

Geeslin, Kimberly. L., and Aarnes Gudmestad. 2008. Comparing interview and written elicitation task in native and non-native data: Do speakers do what we think they do? In Selected Proceedings of the Hispanic Linguistics Symposium. Edited by J. Bruhn de Garavito and E. Valenzuela. Somerville: Cascadilla Proceedings Project, pp. 64-77.

Geeslin, Kimberly L., and Aarnes Gudmestad. 2010. An exploration of the range and frequency of occurrence of forms in potentially variable structures in second-language Spanish. Studies in Second Language Acquisition 32: 433-63. [CrossRef] 
Giancaspro, David. 2013. L2 learners' and heritage speakers' judgments of code-switching at the auxiliary-VP boundary. In Selected Proceedings of the 16th Hispanic Linguistics Symposium. Edited by Jennifer Cabrelli Amaro, Gillian Lord, Ana de Prada Pérez and Jessi Elana Aaron. Somerville: Cascadilla Proceedings Project, pp. 56-69.

Giancaspro, David. 2015. Code-switching at the auxiliary-VP boundary: A comparison of heritage speakers and L2 learners. Linguistic Approaches to Bilingualism 5: 379-407. [CrossRef]

Giancaspro, David. 2017. Heritage Speakers' Production and Comprehension of Lexically- and Contextually-Selected Subjunctive Mood Morphology. Ph.D. dissertation, Rutgers University, New Brunswick, NJ, USA.

González-Vilbazo, Kay, and Luis López. 2011. Some properties of light verbs in code-switching. Lingua 121: 832-50. [CrossRef]

Grosjean, François. 2001. The bilingual's language modes. In One Mind, Two Languages: Bilingual Language Processing. Edited by Janet Nicol. Oxford: Blackwell, pp. 1-22.

Gudmestad, Aarnes. 2006. L2 variation and the Spanish subjunctive: Linguistic features predicting mood selection. In Selected Papers of the 7th Conference on the Acquisition of Spanish and Portuguese as First and Second Languages. Edited by Carol A. Klee and Timothy L. Face. Somerville: Cascadilla Proceedings Project, pp. 170-84.

Gudmestad, Aarnes. 2012. Acquiring a variable structure: An interlanguage analysis of second language mood use in Spanish. Language Learning 62: 373-402. [CrossRef]

Gudmestad, Aarnes. 2013. Tense-aspect distinctions within the subjunctive mood in the Spanish of native speakers and secondlanguage learners. Studies in Hispanic and Lusophone Linguistics 6: 3-35. [CrossRef]

Gumperz, John J. 1982. Discourse Strategies. Cambridge: Cambridge University Press.

Guzzardo Tamargo, Rosa E., and Paola E. Dussias. 2013. Processing of Spanish-English code switches by late bilinguals. In Proceedings of the 37th Boston University Conference on Language Development. Edited by Sarah Baiz, Nora Goldman and Rachel. Hawkes. Somerville: Cascadilla Proceedings Project, pp. 134-46.

Köppe, Regina, and Jürgen M. Meisel. 1995. Code-switching in bilingual first language acquisition. In One Speaker, Two Languages. Edited by Lesley Milroy and Pieter Muysken. Cambridge: Cambridge University Press, pp. 276-301.

Koronkiewicz, Bryan. 2018. Acquiring L1-English L2-Spanish Code-Switching: The Role of Exposure to Language Mixing. Languages 3: 26. [CrossRef]

Królikowska, Marta, Emma Bierings, Anne Beatty-Martínez, Christian Navarro-Torres, Paola Dussias, and M Carmen Parafita Couto. 2019. Gender assignment strategies within the bilingual determiner phrase: Four Spanish-English communities examined. Paper Presented at the 3rd conference on Bilingualism in the Hispanic and Lusophone World, Leiden, The Netherlands, January 9-11.

Lenth, Russell V. 2020. Emmeans: Estimated Marginal Means, aka Least-Squares Means. R Package Version 1.5.2-1. Available online: https:/ /CRAN.R-project.org/package=emmeans (accessed on 1 May 2021).

Leonetti Jungl, Manuel. 1999. El artículo [The article]. In Gramática Descriptiva de la Lengua Española. Edited by Ignacio Bosque and Violeta Demonte. Madrid: Espasa Calpe, pp. 787-891.

Lipski, John. M. 2014. Spanish-English code-switching among low-fluency bilinguals: Towards an expanded typology. Sociolinguistic Studies 8: 23-55. [CrossRef]

Lipski, John M. 2016. The role of unintential/involuntary codeswitching: Did I really say that? In Spanish-English Code-Switching in the Caribbean and the US. Edited by Rosa E. Guzzardo Tamargo, Catherine M. Mazak and M. Carmen Parafita Couto. Amsterdam: John Benjamins, pp. 139-68. [CrossRef]

López, Luis. 2020. Bilingual Grammar: Toward an Integrated Model. Cambridge: Cambridge University Press.

MacSwan, Jeff. 2013. Code-Switching and grammatical theory. In The Handbook of Bilingualism and Multilingualism, 2nd ed. Edited by Tej K. Bhatia and William C. Ritchie. West Sussex: Wiley-Blackwell, pp. 323-50.

Mc Clure, Erica. 1981. Formal and functional aspects of the code-switched discourse of bilingual children. In Latino Language and Communicative Behavior. Edited by Richard P. Duran. Norwood: ABLEX, pp. 69-94.

Meisel, Jürgen M. 1994. Code-switching in young bilingual children: The acquisition of grammatical constraints. Studies in Second Language Acquisition 16: 413-39. [CrossRef]

Meteyard, Lotte, and Robert A.I. Davies. 2020. Best practice guidance for linear mixed-effects models in psychological science. Journal of Memory and Language 112: 104092. [CrossRef]

Montoya, Liliana. 2020. Code-Switching in L2 Spanish: A comparison of French and English learners. Ph.D. dissertation, The University of Western, London, ON, Canada.

Montrul, Silvina, and Roumyana Slabakova. 2003. Competence similarities between native and near-native speakers: An investigation of the preterite/imperfect contrast in Spanish. Studies in Second Language Acquisition 25: 351-98. [CrossRef]

Montrul, Silvina, and Silvia Perpiñán. 2011. Assessing differences and similarities between instructed L2 learners and heritage language learners in their knowledge of Spanish Tense-Aspect and Mood (TAM) Morphology. The Heritage Language Journal 8: 90-133. [CrossRef]

Montrul, Silvina. 2011. Morphological errors in Spanish second language learners and heritage speakers. Studies in Second Language Acquisition 33: 163-92. [CrossRef]

Moreno, Eva M., Kara D. Federmeier, and Marta Kutas. 2002. Switching languages, switching palabras (words): An electrophysiological study of code switching. Brain and Language 80: 188-207. [CrossRef] [PubMed]

Munarriz-Ibarrola, Amaia, Maria-José Ezeizabarrena, Varun DC Arrazola, and M. Carmen Parafita Couto. 2021. Gender assignment strategies and L1 effects in the elicited production of mixed Spanish-Basque DPs. Linguistic Approaches to Bilingualism. [CrossRef] 
Myers-Scotton, Carol, and Janice Jake. 2009. A universal model of code-switching and bilingual language processing and production. In The Cambridge Handbook of Linguistic Code-Switching. Edited by Barbara E. Bullock and Almeida J. Toribio. Cambridge: Cambridge University Press, pp. 336-57.

Parafita Couto, M. Carmen, Miriam Greidanus Romaneli, and Kate Bellamy. 2021. Code-switching at the interface between language, culture, and cognition. Lapurdum: Basque Studies Review. Available online: https://halshs.archives-ouvertes.fr/halshs-03280922 / document (accessed on 1 May 2021).

Poplack, Shana. 1980. Sometimes I'll start a sentence in Spanish y termino en español: Toward a typology of code-switching. Linguistics 18: 581-618. [CrossRef]

Potowski, Kim. 2009. Forms and functions of codeswitching by dual immersion students: A comparison of heritage speaker and L2 children. In First Language Use in Second and Foreign Language Learning. Edited by Miles Turnbull and Jneeifer Diley-O'Cain. Great Britain: Multilingual Matters, pp. 87-114. [CrossRef]

Potowski, Kim, and Mariška Bolyanatz. 2012. Reactions to (in)felicitous codeswitching: Heritage speakers vs. L2 learners. In Selected Proceedings of the 14th Hispanic Linguistics Symposium. Edited by Kimberly Geeslin and Manuel Díaz-Campos. Somerville: Cascadilla Proceedings Project, pp. 116-29.

Prada Pérez, Ana de. 2018. Subject Pronoun Expression and Language Mode in Bilingual Spanish. Studies in Hispanic and Lusophone Linguistics 11: 303-36. [CrossRef]

Prada Pérez, Ana de, and Andrea Hernández. 2017. Examining Code-Switching Performance Theories: Copula Choice in Spanish among Cuban Heritage Speakers. In Cuban Spanish Dialectology: Variation, Contact and Change. Edited by Alejandro Cuza. Washington, DC: Georgetown University Press, pp. 271-90.

Prada Pérez, Ana de, Nicholas Feroce, and Lillian Kennedy. 2021. The Use of Default Forms in Codeswitching: Mood Selection in Spanish. Linguistic Approaches to Bilingualism. Advance online publication. [CrossRef]

Quesada, Margaret L. 1996. Interlanguage variability of the Spanish subjunctive. Estudios de Lingüística Aplicada 23/24: 358-71. [CrossRef]

Quesada, Margaret L. 1998. L2 acquisition of the Spanish subjunctive mood and prototype schema development. Spanish Applied Linguistics 2: 1-23.

Rakowsky, Amy B. 1989. A study of Intra-Sentential Code-Switching in Spanish-English Bilinguals and Second Language Learners. Ph.D. dissertation, Brown University, Providence, RI, USA.

Raymond, Chase. W. 2012. La gramática de la alternancia de código: El uso del indicativo y del subjuntivo en oraciones bilingües. Revista Internacional de Lingüística Iberoamericana: RILI 19: 213-36.

R Core Team. 2017. R: A Language and Environment for Statistical Computing. Vienna: R Foundation for Statistical Computing.

Rubin, Edward, and Almeida J. Toribio. 1996. The role of functional categories in bilingual children's language mixing and differentiation. World Englishes 15: 385-93. [CrossRef]

Silva-Corvalán, Carmen. 1994. The gradual loss of mood distinctions in Los Angeles Spanish. Language Variation and Change 6: 255-72. [CrossRef]

Suurmeijer, Luuk, M. Carmen Parafita Couto, and Marianne Gullberg. 2020. Structural and extralinguistic aspects of code-switching: Evidence from Papiamentu-Dutch auditory sentence matching. Frontiers in Psychology 11: 592266. [CrossRef]

Toribio, Almeida J. 2001. Accessing bilingual code-switching competence. International Journal of Bilingualism 5: 403-36. [CrossRef]

Toribio, Almeida J. 2004. Convergence as an optimization strategy in bilingual speech: Evidence from code-switching. Bilingualism: Language and Cognition 7: 165-73. [CrossRef]

Toribio, Almeida J. 2017. The future of code-switching research. In Code-switching-Experimental Answers to Theoretical Questions: In Honor of Kay González-Vilbazo. Edited by Luis López. Amsterdam: John Benjamins, pp. 257-67. [CrossRef]

Toribio, Almeida J., Regina Roebuck, James Lantolf, and A. Perrone. 1993. Syntactic Constraints on Code-Switching: Evidence of Abstract Knowledge in Second Language Acquisition. Ithaca: Cornell University.

Torres Cacoullos, Rena, and Catherine E. Travis. 2011. Testing convergence via code-switching: Priming and the structure of variable subject expression. International Journal of Bilingualism 15: 241-67. [CrossRef]

Torres Cacoullos, Rena, and Catherine E. Travis. 2016. Two languages, one effect: Structural priming in spontaneous code-switching. International Journal of Bilingualism 19: 733-53. [CrossRef]

Torres Cacoullos, Rena, and Catherine E. Travis. 2018. Bilingualism in the Community: Code-Switching and Grammars in Contact. Cambridge: Cambridge University Press.

Valdés, Guadalupe. 1976. Social interaction and code-switching patterns. In Bilingualism in the Bicentennial and Beyond. Edited by Gary D. Keller, Richard V. Teschner and Silvia Viera. Jamaica: Bilingual Press, pp. 52-85.

Valdés Kroff, Jorge. 2016. Mixed NPs in Spanish-English bilingual speech: Using a corpus-based approach to inform models of sentence processing. In Spanish-English Code-Switching in the Caribbean and the US. Edited by Rosa E. Guzzardo Tamargo, Catherine M. Mazak and M. Carmen Parafita Couto. Amsterdam: John Benjamins, pp. 281-300. [CrossRef]

van Osch, Brechje, and Petra Sleeman. 2018. Spanish heritage speakers in the Netherlands: Linguistic patterns in the judgment and production of mood. International Journal of Bilingualism 22: 513-29. [CrossRef]

Viner, Kevin. M. 2016. Second-generation NYC bilinguals' use of the Spanish subjunctive in obligatory contexts. Spanish in Context 13: 343-70. [CrossRef] 
Zentella, Ana Celia. 1981. Hablamos los dos. We speak both: Growing up bilingual in el barrio. Doctoral dissertation, University of Pennsylvania, Philadelphia, PA, USA.

Zentella, Ana Celia. 1997. Growing up Bilingual. Malden: Blackwell. 